\title{
The Relationship between Personality Traits, Academic Self-Efficacy and Academic Adaptation among University Students in Jordan
}

\author{
Mohammed H. Abood ${ }^{1}$, Bassam H. Alharbi ${ }^{1}$, Fatin Mhaidat ${ }^{1}$ \& Ahmad M. Gazo $^{1}$ \\ ${ }^{1}$ Department of Educational Psychology, Faculty of Educational Science, The Hashemite University, Zarqa, Jordan. \\ Correspondence: Mohammad H. Abood, Department of Educational Psychology, Faculty of Educational Science, \\ The Hashemite University, Zarqa, Jordan. E-mail: abood892000@yahoo.com \\ Received: February 17, 2020 \\ Accepted: March 11, 2020 \\ Online Published: March 12, 2020 \\ doi:10.5430/ijhe.v9n3p120 \\ URL: https://doi.org/10.5430/ijhe.v9n3p120
}

\begin{abstract}
The current study investigates the relationship between personality traits according to the big five personality factors model, academic self-efficacy and academic adaptation among Hashemite University students in light of gender and specialization. The purposive sample consisted of 546 under graduated students, 258 males and 306 females. Three scales are used: the Five Factor Model (FFM), for academic self-efficacy and for academic adaption. The results show statistically significant differences in the average of participants' degrees attributed to efficacy and academic adaption in favor of females and scientific specializations. They also show that agreeableness, conscientiousness, openness to experience, extroversion and neuroticism are most common among university students, with a statistically significant positive correlation between extroversion, openness to experience, academic self-efficacy and academic adaption and a negative correlation between neuroticism, conscientiousness, academic self-efficacy and academic adaption. No correlation was found between agreeableness and these two variables.
\end{abstract}

Keywords: personality traits, academic self-efficacy, academic adaptation, university students

\section{Introduction}

In the present study there are three variables, which are covered as follows:

\subsection{Personality Traits}

Analysis of personality has a significant place in psychology because understanding it correctly helps in understanding human nature leadings to better interaction and better expectations of behavior. Personality is one of the most complex and interrelated subjects in humans as a common system of innate and required psychological factors contributing to establishing the social environment from childhood to old age (Pervin \& John, 2001).

Personality is the frame distinguishing one individual from another; each human has his/her own world, abilities, and possibilities. Furthermore, personality is strongly related to cultural content and its influence on upbringing, how the individual identifies and satisfies needs, how the individual expresses his/her reactions, his/her relations to others and distinguishing right from wrong. Thus, personality is not a result of biological or social factors alone but of the interaction between epigenetic and environmental factors together (Eysenck \& Wilson, 1975).

Humans have long attempted to classify personality into particular patterns and general traits, according to physical traits and external features. According to the traits spectrum, personality is combined of several traits that are a relatively continuous permanent feature (Santrock, 2003). Many theoretical frameworks have been developed by scientists to classify personal traits.

Jungian archetypes theory aimed to identify similar traits for each personality type, as a particular archetype. Jung himself divided personality into two main types: introversion and extroversion. An introverted person is unsociable and prefers isolation. while extroverts likes to socialize with others (Crow, 1968, p. 164).Characteristics theory has also had a great effect in analyzing personality and trying to classify individuals according to the degree of each characteristic exhibited(Deraad, 2000).

Traits are physical, emotional, mental, and social features, whether innate or acquired. They distinguishes the individual and helps in understanding him/her. All port tried to restrict the number personal traits identified, but there are overwhelming numbers of them. Therefore, scientists considered a model that describes the basic dimensions of 
personalities by gathering related traits and classifying them under an independent pattern that can be generalized through individuals and cultures (Ewen, 1998).

To accomplish this, the researchers applied factor analysis, a method based on scientific brevity of searching about the basic units of personality gathered by shared factors to give a better interpretation of behaviour (Digman, 1990). Through factor analysis, Cattell determined 16 basic factors of personality (16PF), which Eysenck reduced to three dimensions: level of extroversion, which is divided into extreme extroversion and extreme introversion, neuroticism which brings together features of emotional stability and instability, and psychotic, which detects mental patients who are aggressive and cruel (Deraad,2000).

Using the same analysis, Costa and McCrae determined five dimensions of personality: extroversion, neuroticism, openness to experience conscientiousness and agreeableness. This pattern is key in analyzing personality because it is a scientific classification of personality traits in the least numbers of factors, can be classified by the big five personality traits as the Five Factors Model.

McCrae and Costa (1997) explained that extroversion is characterized by warmth, gregariousness, assertiveness, activity, excitement-seeking, and positive emotions. In this dimension, a low degree indicates withdrawal, reservation, and being antisocial. Neuroticism is characterized by anxiety, hostility, depression, self-consciousness, stress and impulsiveness, a low degree of this dimension indicates emotional stability and the ability to resist pressure. Openness to experience is characterized by fantasy, aesthetic feelings, actions, ideas, values and beauty, a low degree of this dimension indicates impasse of fantasy and dogmatism.

Agreeableness is characterized by trust, straightforwardness, altruism, compliance, modesty, tenderness and thoughtfulness (John \&Naumann,2007), low degree indicates aggression and selfishness. Conscientiousness is characterized by competences, order, dutifulness, deliberation, self-discipline, and achievement-striving, a low degree indicates indifference and lack of interest in the system.

\subsection{Self-Efficacy}

Self-efficacy indicates that the individual believes in his/her ability to organize and implement the practical plans required to achieve goals and control events. Thus, the level of self-efficacy can affect the individual's motivation, degree of effort and initiative in facing challenges. It also affects his/her way of thinking and interaction, which means that if the individual believes that he/she can achieve the goals then he/she will try to make the thing happen.

Rahil, et al.(2006) claim that self-efficacy is the individual's trust in his/ her performance ability in different fields. Individual success accordingly depends on facing problems and achieving goals. Self-efficacy is the individual's belief in his/her abilities and how to employ his/her skills in certain circumstances. it is the ability to do what is manageable. Bandura (1993) defines self-efficacy in the academic field as belief in one's ability to achieve academic tasks. It is the process in which students develop a positive trend about their abilities (Hassanzadeh, Ebrahimi, \& Mahidinejad, 2012). Zimmerman (1995) defines it as personal judgments on students' abilities in organizing and implementing educational curriculums to achieve a high level of academic achievement.

Bandura (1997) indicates that self-efficacy is not hereditary but is gained through experiment, because these beliefs begin in childhood and continue throughout life, developing to employ past experiences to future situations. Self-efficacy develops as a result of the close relationship between environment, personality traits and behaviour (Pajares, 1998).

Bandura (1993) emphasized several main sources that strengthen feelings related to self-efficacy: parents, teachers, and friends. Parents have a key role in childhood by arranging the goals that the child has to achieved and showing the best goals achieved with others: in other words, understanding successful experiences and showing that suitable patterns that have already been established can enhance the individual's self-efficacy, through verbal persuasion and encouragement (Bandura, 1997).

On one hand, self-efficacy has a major role in self-adaption because it helps the individual to feel control over his/her behaviour, environment and facing life's challenges. As a result, an individual will feel pleased and happy(Maddux, 2000). On the other, Bandura (1993) points out that low self-efficacy contributes to depression because such people usually think that their ability to face life's challenges is less than others'. Low self-efficacy affects the immune system because the individual believes that he/she has lost control of environmental demands, raising the possibility of infection. Self-efficacy, indeed, plays a major role in every side of personality because of its effect on behaviour and ideology. Bandura (1998) indicates that academic self-efficacy enhances academic adaptation, positive optimism, achievement, and flexibility in dealing with difficulties: individuals with low academic self-efficacy have low aspirations and less commitment to achieving the required goals. 
Harris (1990) indicates that academic self-efficacy is important as it affects a student's choice of his/her academic assignments and activities. It also affects the continuity of making efforts and persistence to achieve goals, while students with low self-efficacy cannot deal with hard situations to avoid failure. Chemers, $\mathrm{Hu}$ and Garcia (2001) show a direct or indirect strong correlation between academic self-efficacy and academic performance because it affects student's expectations about their ability to deal with pressure and academic requirements.

Schunk (2003) emphasizes that individuals with high efficiency think that they can accomplish advanced tasks while people with low efficiency tend to give up easily and feel lazy. Greene etal. (2004) conducted a study on 220 students to investigate the correlation between academic self-efficacy and educational performance: their results showed a direct positive correlation between both, and the importance of academic self-efficacy in successful learning. Individuals with high self-efficacy invest their efforts and fight for a longer time to accomplish their goals: they recover fast when setbacks happen. Bandura et al.(1996) conducted a study to investigate the most influential factors on the study achievements of a group of children: they include the parent's academic performance and some behavioral problems. In addition to self-efficacy. The results show that academic self-efficacy and ambition are the most influential variables on academic achievement.

Accordingly, academic self-efficacy has a key role in the third strand, academic adaption: it is a major issue for educators because it is related to many influencing factors in individual life, especially mental health and success. Academic adaption is the learner's ability to form appropriate relationships with teachers and colleagues, compatibility with the examination systems and assignments, and coexistence of university and personal objectives (Nyamayaro \& Saravanan, 2013).Therefore, academic adaptation is one of the most important manifestations of general adaptation and satisfaction and leads to better grades and academic efficacy (Zhang, 2009).

\subsection{Academic Adaptation}

Academic adaptation has a major role in the student's life because it is one of the main requirements for success and continuity of study: it is an indicator of the student's mental health. playing a major role of his/her relationship with the educational institution, which cares not only for the mental and cognitive side but also with the student's ability to adapt to educational subjects and the academic environment.

The academic adaptation of the learner involves many pictures and behavioral practices, summarized as concentrating in the classroom, participation in class discussions, completing tasks on time, positive feeling towards the educational institution, compliance with instructions and satisfaction with specializations (Alavi\&Mansor,2011).

Many studies have been conducted on the relationship between academic adaptation and a variety of traits in university' students. Stover (2001), for example, conducted a study about academic adaptation in light of academic self-efficacy, academic performance and some personality traits, with a sample of 285 students of Southwestern University in Texas. The results indicate a statistically significant predictive ability of academic self-efficacy with academic adaptation.

Lent, et al.(2009) indicate that students with high self-efficacy gain higher marks in their specializations than those with low self-efficacy. Accordingly, as academic self-efficacy is influenced by the nature of the student's personality, it is considered an effective indicator of the way of thinking, emotion, and behaviour. According to Alport (1967), personality is the dynamic organization of psychological and physical functions which determine an individual's behaviors and thought.

The current study examines the correlation between personality traits, academic self-efficacy and academic adaptation in students in one Jordanian university.

\section{The Research Problem}

The personality of each individual is distinguished by his/her abilities and possibilities. Personality influences individuals' different behaviours, emotions and thinking, and thus their ability to adapt to all aspects of life. Academic adaptation is subject to many influencing factors in the individual's life, social, family or academic levels. Students with high self-efficacy develop positive personality traits, thus improving academic adaptation and increasing self-confidence and self-esteem. Academic self-efficacy is one of the most important factors that positively affects students' academic grades at different levels and different subjects.

This study focuses on university students at an important stage of acquiring skills and knowledge. The researcher hypothesizes that personality traits have a major role in self-efficacy and academic adaptation. This relationship involves what Bandura called an inevitable exchange between personality factors and behaviour. The study problem is addressed by the following question: 
- What is the relationship between personality traits and both academic self-efficacy and academic adaptation by students of Hashemite University?

This question is divided into the next questions concerning these students:

-1. What are their most common personality traits?

-2 . What is their level of academic self-efficacy?

-3. Dose the level of academic self-efficacy vary by gender and academic specialization?-4. What is their level of academic adaptation?

-5 . Dose the level of academic adaptation vary in accordance with gender (male, female) and academic specialization (science, humanities)?

-6. Is there a statistically significant correlation between personality traits, academic self-efficacy, and academic adaptation?

\section{Aims and Hypotheses of the Study}

The current study aims to investigate the nature of the relationship between personality traits, academic self-efficacy and academic adaption of students at the Hashemite University in Jordan.

\section{Significance of the Study}

The significance of the study covers two important concepts in learning and academic achievement motivation: academic self-efficacy and academic adaptation: it means discovering the relationship between personality traits, academic self-efficacy and academic adaption of the students. The results will be valuable in planning for educational and indicative programs to consider academic self-efficacy and academic adaptation with commensurate personality traits of students since self-efficacy and academic adaptation play a major role in academic fields.

\section{Limitation of Study}

The research investigates only undergraduate students of Hashemite University in Jordan, specifically those registered in the second semester of 2019-2020. Consequently, the results cannot be generalized beyond the study population and similar ones.

\section{Methodology}

\subsection{Survey Sample}

- $\quad$ Pilot study: the researchers chose a random sample of 40 female and male students from the original study population, then applied methods of analysis to check that they are appropriate and to check validity by suitable statistical methods.

- $\quad$ Field sample: the sample consisted of (564) students in their first, second, third and fourth years in the Hashemite university, 258 male and 306 female. Table 1 illustrates the distribution of the sample according to the variables.

Table 1. Distribution of the sample according to the variables

\begin{tabular}{cccc}
\hline Variables & Level & Frequency & Percentage \\
\hline Gender & Males & 258 & 45.7 \\
& Females & 306 & 54.3 \\
& Total & 564 & 100 \\
Academic & Science & 286 & 50.7 \\
specialization & Humanities & 278 & 49.3 \\
& Total & 564 & 100 \\
\hline
\end{tabular}

\subsection{Study Instruments}

The researchers used three instruments to achieve the study goals:

\section{Five Factors Model of personality}

The researcher used Costa and McCrae's (1992) framework: the big five factors of personality consists of 60 items equally distributed among the five branches (extroversion, neuroticism, openness to experience, conscientiousness 
and agreeableness). The researchers checked the validity of internal consistency by calculating the correlation coefficient of each item and the degree it belongs to; hence the correlation coefficients range between 0.59 and 0.26. Using Cronbach's- Alpha, the measure of stability is $0.74-0.77$ which is acceptable. A 5-point Likert scale is used $(1=$ very low degree of applicability, $2=$ low degree of applicability, $3=$ medially applicable, $4=$ highly applicable, $5=$ strongly high degree of applicability). It must be mentioned that there are negative items reversed before analyzing the data.

\section{College Academic Self-efficacy Inventory (CASI)}

The researchers used CASI by Owen and Froman(1988).Its 33 items were tested with the pilot sample of 40 students to measure reliability correlation, coefficients were measured in accordance to the total degree $(0.26-0.67)$.

All correlation coefficients were statistically significant. Reliability was measured by internal consistency according to Cronbach's Alpha, on the independent group of 40 (0.81). The overall potential ranges from 33 points for the highest amount of confidence to 165 points for the lowest.

\section{Academic Adaptation of University Students}

Henry Borrow developed this measurement, consisting of 39 items and follows a 5-point Likert scale. The validity of this measurement was $0.25-0.56$, reliability was measured by internal consistency $(0.75)$ and by test-retest $(0.81)$ which means that this measurement is reliable.

\subsection{Data Analysis}

The study sample completed the study scales in collective classroom situations. The data collection process took three weeks. Descriptive statistics were used as means, standard deviations, to answer the study questions one, two and five. Two Way ANOVA were used to answer the study questions three and four. While to answer the study question six Pearson correlation were used. Data were analyzed by using Statistical Package for Social Sciences (SPSS)

\section{Results}

\section{Question one: What are the most common personality traits of Hashemite University students?}

To answer this question, means and standard deviation were calculated on the personality traits scale, as shown in Table 2.

Table 2. Means and standard deviation of common personality traits

\begin{tabular}{cccc}
\hline Variable & Means & Standard deviation & Rank \\
\hline Neuroticism & 3.20 & 0.83 & 5 \\
Conscientiousness & 3.72 & 0.80 & 2 \\
Openness to Experience & 3.65 & 0.70 & 3 \\
Agreeableness & 3.96 & 0.55 & 1 \\
Extroversion & 3.51 & 0.91 & 4 \\
\hline
\end{tabular}

Table 2 reveals that agreeableness is the most common personality traits, mean 3.96.

\section{Question two: What is their level of academic self-efficacy?}

Means and standard deviation were calculated on the academic self-efficacy scale, as shown in Table 3.

Table 3. Means and standard deviation of academic self-efficacy level

\begin{tabular}{c|c|c|c}
\hline Variable & Mean & $\begin{array}{c}\text { Standard } \\
\text { deviation }\end{array}$ & Level \\
\hline Academic self-efficacy & 3.75 & 0.41 & High \\
\hline
\end{tabular}

The table indicates that students have a high level of academic self-efficacy. mean3.75

Question three: Dose the level of academic self-efficacy vary in accordance with gender (male, female) and academic specialization (science, humanities)?

Means and standard deviation were calculated on the academic self-efficacy scale by gender and academic specialization, as in Table 4. 
Table 4. Means and standard deviation of academic self-efficacy scale by gender and academic specialization

\begin{tabular}{cccc}
\hline Variable & Level & \multicolumn{2}{c}{ Academic self-efficacy } \\
\cline { 3 - 4 } & & Mean & Standard deviation \\
\hline Gender & Female & 3.85 & 0.33 \\
& Male & 3.67 & 0.45 \\
Academic & Humanities & 3.54 & 0.31 \\
specialization & Science & 3.97 & 0.38
\end{tabular}

Table (4) indicates significant differences in the level of academic self-efficacy by gender and by academic specialization. A Two Way ANOVA was therefore used to determine the significance of these differences, see Table 5.

Table 5. Results of two ways ANOVA analysis of the impact of gender and academic specialization on academic self-efficacy

\begin{tabular}{cccccc}
\hline $\begin{array}{c}\text { Source of } \\
\text { significance }\end{array}$ & $\begin{array}{c}\text { Sum of } \\
\text { squares }\end{array}$ & $\begin{array}{c}\text { Degree of } \\
\text { freedom }\end{array}$ & $\begin{array}{c}\text { Average of } \\
\text { squares }\end{array}$ & F value & $\begin{array}{c}\text { Level of } \\
\text { significance }\end{array}$ \\
\hline Gender & 3.291 & 1 & 3.291 & 28.046 & 0.00 \\
Specialization & 24.760 & 1 & 24.760 & 210.993 & 0.00 \\
Error & 65.832 & 561 & 0.117 & & \\
corrected total & 94.829 & 563 & & &
\end{tabular}

According to Table 5, there is statistical significance in the level of academic self-efficacy by gender $(\mathrm{F}=28.046)$, table (4shows that), the mean for females (3.85) is higher than males (3.67). There are also statistically significant differences in the level of academic self-efficacy according to specialization $(\mathrm{F}=210.993)$, the mean for scientific specializations (3.97) is higher than for humanities (3.54).

\section{Question four: What is their level of academic adaptation?}

The means and standard deviation were calculated on the academic adaptation scale, as in Table 6.

Table 6. Means and standard deviations of academic adaptation

\begin{tabular}{c|c|c|c}
\hline Variable & Means & Standard deviation & Level \\
\hline Academic adaptation & 2.43 & 0.36 & High
\end{tabular}

The level of academic adaptation is high (mean=2.43).

Question five: Dose the level of academic adaptation vary in accordance with gender (male, female) and academic specialization (science, humanities)?

Means and standard deviation were calculated on the academic adaptation scale by gender and academic specialization see Table 7 .

Table 7. Means and standard deviation of academic adaptation scale by gender and academic specialization

\begin{tabular}{cccc}
\hline Variable & Level & \multicolumn{2}{c}{ Academic self-efficacy } \\
\cline { 3 - 4 } & & Mean & Standard deviation \\
\hline Gender & Male & 2.39 & 0.39 \\
& Female & 2.46 & 0.33 \\
Academic & Humanities & 2.11 & 0.22 \\
specialization & Science & 2.75 & 0.06
\end{tabular}

Table 7 indicates significant differences by gender and academic specialization: the results of the two way ANOVA test determine the significance of these differences ( Table 8). 
Table 8. Results of Two Ways ANOVA analysis of the impact of gender and academic specialization on academic adaptation

\begin{tabular}{cccccc}
\hline $\begin{array}{c}\text { Source of } \\
\text { significance }\end{array}$ & $\begin{array}{c}\text { Sum of } \\
\text { squares }\end{array}$ & $\begin{array}{c}\text { Degree of } \\
\text { freedom }\end{array}$ & $\begin{array}{c}\text { Average of } \\
\text { squares }\end{array}$ & F value & $\begin{array}{c}\text { Level of } \\
\text { significance }\end{array}$ \\
\hline Gender & 1.286 & 1 & 1.286 & 52.071 & 0.00 \\
Specialization & 59.483 & 1 & 59.483 & 2408.117 & 0.00 \\
Error & 13.857 & 561 & 0.025 & & \\
Total & 73.918 & 563 & & &
\end{tabular}

According to Table 8, there is a statistical significance in the level of academic adaptation by gender ( $\mathrm{F}=52.071)$ the mean for females (2.46) was higher than for males (2.39). There is also a statistically significant difference in the level of academic adaptation according to specialization $(\mathrm{F}=2408.117)$ mean for humanities $(2.75)$ is higher than for scientific specializations (2.11).

Questions six and seven: Is there a statistically significant correlation between personality traits and both academic self- efficacy and academic adaptation of university students?

To answer this question, Pearson correlation was measured for the answers on personality traits, academic self-efficacy and academic adaption, as presented in Table 9.

Table 9. Pearson correlation of personality traits, academic self-efficacy, and academic adaptation

\begin{tabular}{cccccc}
\hline Variables & \multicolumn{5}{c}{ Personality traits } \\
\hline & $\begin{array}{c}\text { Openness to } \\
\text { experience }\end{array}$ & Extroversion & Neuroticism & Agreeableness & Conscientiousness \\
\hline $\begin{array}{c}\text { Academic } \\
\text { self-efficacy }\end{array}$ & $* 0.31$ & $* 0.18$ & $*-0.23$ & -0.01 & $*_{-0.12}$ \\
$\begin{array}{c}\text { Academic } \\
\text { adaption }\end{array}$ & $* 0.43$ & $* 0.67$ & $*-0.50$ & -0.08 & $*-0.45$ \\
\hline
\end{tabular}

There is a positive statistically significant correlation between extroversion, openness to experience and both academic self-efficacy and academic adaption in addition to a negative statistically significant correlation between neuroticism, conscientiousness and both academic self-efficacy and academic adaption. No correlation was found between agreeableness and either academic self-efficacy or academic adaptation.

\section{Discussion}

The results for the first question on the big five personality traits indicated that agreeableness is the most common among the participants. Agreeableness is characterized by tolerance, selflessness, positive relationships and cooperating with others. Conscientiousness was in second place, characterized by competence, order, dutifulness, and self-discipline. Researchers attribute this to cultural factors and Jordanian customs, in addition to the fact that students are clinging to their own moral values.

The third trait is openness to experience, which is characterized by flexibility and acceptance of new things, the technical development and globalization have a role in encouraging students to be open and curious. Extroversion is in fourth place, it is characterized by vitality and activity in addressing economic circumstances and the pressures of life. Neuroticism, characterized by anxiety, sadness, worry, and tension, is in the last place, possibly because of students' ability to adapt to circumstances and reduce anxiety through their social and personal skills.

The results showed a high level of academic self-efficacy, reasons may include the university use of modern techniques in the classroom which encourage students, motivate them and increase their self-confidence. There was a statistical significance in academic self-efficacy according to gender, in favor of females. Females are more driven, following-up their studies and working harder to prove themselves, while males have a pessimistic outlook on the future with a poor chances of employment.

There are also statistically significant differences academic self-efficacy by specialization, in favor of the sciences. This result agrees with others (Bandura,1996; Harris, 1990; Zemmerman, 1990).asserting that highly self-efficient individuals accomplish hard educational tasks. The researchers claim that students specializing in science make an effort because through their hard subjects the acquire high efficacy in comparison with students of humanities who 
may feel bored. The difference may also arise the educational environment, with laboratory provision and scientific instruments, while the humanities do not have a practical side. The results indicated a high level of academic adaptation, resulting from the educational environment taking into account requirements of the curriculum and practical's, and training courses to attract students to the university and improve their skills. However, there was a statistically significant difference in the level of academic adaptation in accordance with gender, in favor of females. There are more female than male students, facilitating their integration in to the environment; females also focus on the academic side more than males, who tend to spend time on other activities such as finding a source of income, which affects their level of academic adaptation negatively.

The results showed a positive significant correlation between extroversion, openness to experience and both academic self-efficacy and academic adaptation; individuals with these two traits are active, enthusiastic and open to new ideas, which are reflected in their self-realization and make them more efficient (Sink, 1991Harris (1990) indicates that self-efficacy is influenced by student activities. Extroversion and openness to experience help in building good relations with teachers and colleagues in addition to participating in different activities and being open to the latest updates in technology. Consequently integrating with the university environment.

There was a positive significant correlation between neuroticism, conscientiousness and both academic self-efficacy and academic adaption. Neuroticism is a negative emotional state in which the individual loses control of emotional stability and feels angry and stressed. Conscientiousness is characterized by obligation and self-discipline, with little time spent on other university activities. Therefore, academic self-efficacy and academic adaptation are lower.

Agreeableness does not correlate with either academic self-efficacy or academic adaptation because it depends on tolerance and selflessness, which do not influence activity and efficacy as much as extroversion and being open to experience.

\section{Recommendations}

In light of these results, the researcher recommends:

- Developing indicative programmers to help students improve their level of extroversion and openness to experience. In light of their positive correlation with academic self-efficacy and academic adaptation; and to reduce the level of neuroticism because of its negative correlation with the variables.

- Conducting more studies about the relationship between personality traits and other academic variables.

\section{Authors' contributions}

MA, BH and FM designed the study. BH,FM and AG performed the study. MA analyzed the data and drafted the manuscript. MA, BH,FM and AG participated in revising the manuscript. All authors approved the final manuscript.

\section{References}

Alavi, M. \& Mansor, S. (2011). Categories of problems among international students in university technology Malaysia. Journal of procedia-social and behavioral sciences, 30, 1581-1587.

Allport, G. W. \& Ross, J.M (1967). Personal religious orientation and prejudice. Journal of Personality and Social Psychology, 5, 432-443. http://dx.doi.org/10.1037/h0021212

Baker, R.W. \& Sirke, B. (1999). Students adaptation to college questionnaire. Los Angeles, Ca: western psychological services.

Bandura, A. (1988). perceived self -Efficacy in coping with cognitive 22- stressors and opioid Activation. Journal of Personality and Social psychology, 55, 222-333.

Bandura, A. (1993). Perceived self-efficacy in cognitive development and functioning. Educational Psychologist, 28(2), 117-148. http://dx.doi.org/10.1207/s15326985ep2802_3

Bandura, A., Barbaranelli, C., Caprara, G. \& Pastorelli, C. (1996). Multifaceted impact of self-efficacy beliefs on academic functioning. Child Development, 67, 1206-1222. http://dx.doi.org/10.2307/1131888

Bandura.A. (1997). Self-efficacy. Harvard Mental Health Letter, 13(9), 3-4.

Chemers, M. M., Hu, L. \& Garcia, B. F. (2001). Academic self-efficacy and first-year college student performance and adjustment. Journal of Educational Psychology, 93(1), 55-64. http://dx.doi.org/10.1037/0022-0663.93.1.55

Crow, Lester D. (1968). Psychology of Human Adjustment. New York: Alfred .A. Knopf. 
DeRaad, P. (2000). The Big Five Personality Factors, the Psychology Approach to Personality. Hogrefe \& Huber Publishers. Germany.

Digman, J.M. (1990). Personality structure: Emergence of the five-factor model. Annual Review of Psychology, 41, 414-470. http://dx.doi.org/10.1146/annurev.ps.41.020190.002221

Ewen, R. (1998). An Introduction to Theories of Personality. Mahwah, Nj: Lawrence Erlbaum Associates. http://dx.doi.org/10.4324/9781410607287

Eysenck, H. J. \& Wilson, Glenn. (1975). Know your own personality. London, Penguin Books.

Greene, B. A., Miller, R.B., Crowson, M., Duke, B. L. \& Akey, K. L. (2004). Predicting high school students' cognitive engagement and achievement: Contributions of classroom perceptions and motivation. Contemporary Educational Psychology, 29, 462-482. http://dx.doi.org/10.1016/j.cedpsych.2004.01.006

Harris, C. A., Miller, S. P. \& Mercer, C. D. (1995). Teaching initial multiplication skills to students with disabilities in general education classrooms. Learning Disabilities Research \& Practice, 10, 180-195.

Hassanzadeh, R., Ebrahimi, S. \& Mahdinejad, G. (2012). Studying test anxiety and its relationship with self-efficacy, meta-cognitive beliefs, and some effective predictable variables. European Journal of Social Sciences, 30(4), 511-522

John, O.P. \& Naumann, L.P. (2007). Correlation of BFI scales and self-reported act frequencies in an undergraduate sample. Unpublished data, institute of personality and social research, university of California at Berkeley.

Lent, R., Taveira, M., Sheu, H. \& Singley, D. (2009). Social cognitive predictors of academic adjustment and life satisfaction in Portuguese. College students: A longitudinal analysis. Vcal-Behave, 74, 190-198. http://dx.doi.org/10.1016/j.jvb.2008.12.006

Maddux, E. James. (2000). Self-efficacy: The power of believing you can. handbook of positive psychology. New York: Oxford University Press.

McCrae, R. \& Costa, P. (1997). Personality Trait Structure as a Human Universal. American Psychology, 52, 509-517. http://dx.doi.org/10.1037/0003-066X.52.5.509

Nyamayaro, P. \& Saravanan, C. (2013). The relationship between adjustment and negative emotional states among first-year medical students. Asian Journal of Social Sciences \& Humanities, 2(3), 2070-278.

Owen, S. V. \& Froman, R. D. (1988). Development of a College Academic Self-Efficacy Scale. Proceedings of the Annual Meeting of the National Council on Measurement in Education, New Orleans.

Pajares, F. (1996). Self-efficacy beliefs in academic settings. Review of Educational Research, 66, 543-578. http://dx.doi.org/10.3102/00346543066004543

Pervin, L. \& John, O. (2001). Personality: Theory and Research. 8th, University of California, Berkeley, New York.

Rahil, M., Habibah, E., Loh, S. C., Muhd, F. M. Nooreen, N. \& Maria, C. A. (2006). The relationship between students' self- efficacy and their English language achievement. Journal Pendidikdan Pendidikan, 21, 61-71.

Schunk, D. H. (1991). Self-efficacy and academic motivation. Educational. http://dx.doi.org/10.1207/s15326985ep2603\&4_2

Stanrock, J.W. (2003). Psychology. (7th ed), Boston, McGraw Hill.

Stover, S. (2001). Multiple predictors of college adjustment and academic performance for undergraduates in the first year semester. Unpublished doctoral dissertation, North Texas University, north Texas.

Tino, V. (1996). Reconstructing the first year of college plan. Higher Edu, 25, 1-6.

Zhang, W. (2009). Academic adaptation experiences of Chinese graduate students at J.F. Oberlin University. Unpublished master dissertation, universities loslo, Norway.

Zimmerman, B. J. (1995). Self-efficacy and educational development. New York: Cambridge University Press. http://dx.doi.org/10.1017/CBO9780511527692.009 